\title{
The future of internal medicine in the United States and Poland
}

\begin{abstract}
Internal medicine physicians are critical to the health of the population. Internal medicine doctors also bring cost savings in health care because they treat many systems in the body and treat the patients in a holistic manner. However, the popularity of the specialty of internal medicine is declining. This is due to the decreased compensation that internal medicine doctors obtain when compared to their colleagues who specialize in other fields. The decline in number of physicians specializing in internal medicine causes a decrease in the health of the population. Governments and policy makers must look for ways to reverse the trend of doctors not specializing in internal medicine.
\end{abstract}

Keywords: internal medicine, specialization.

DOI: $10.2478 /$ pjph-2014-0011

\section{INTRODUCTION}

Internal medicine physicians are specialists who apply clinical expertise and scientific knowledge to diagnose, treat, and give care to adults across the continuum from wellness to complicated illness [1]. The phrase internal medicine comes from the German word "Innere Medizin", made popular in Germany at the end of the $19^{\text {th }}$ century to define doctors who unified the science of the laboratory and caring for patients [2]. Many American physicians who studied medicine at the beginning of the 20th century in Germany brought this concept to the U.S.A. Hence, the term "internal medicine" was embraced.

Internists in the U.S.A. must go through pre-medical education in the form of a four-year undergraduate degree before attending medical school for 4 years. Medical students are required to pass the United State Medical Licensing Examinations before they can undertake supervised postgraduate training as a resident for three years. Organizations in the United States responsible for certification of trained internists include the Board of Certification in Internal Medicine, the American Board of Internal Medicine and the American Osteopathic Board of Internal Medicine [3-5]. Licensed internists can work at a hospital as a hospitalist or at an outpatient clinic where they provide primary care.

Many research and surveys have documented the shortage of physicians in the United States, especially in the specialty of Internal Medicine. The situation is described in the publication released by the American College of Physicians in 2006 "The Impending Collapse of Primary Care Medicine and Its Implications for the State of the Nation's Health Care". There has been a decline in the amount of medical students going into primary care during a time of increasing demand for primary care; this is due to increase in the amount of people with chronic diseases and the long term care needs of an aging population. The authors recommend implementing the advanced medical home model, creating financial incentives, improving quality and efficiency and reforming reimbursement policies to solve this medical crisis [6].

The population growth and aging will increase family physician and general internist workload by $29 \%$ between 2005 and 2025. A deficit of 35,000-44,000 adult care generalists is also predicted [7]. A 2008 study by the Association of American Medical Colleges (AAMC) Center for Workforce Studies that estimates upcoming supply and demand for doctors found that a nationwide deficiency is driven by factors such as the increase in the population, an increase in the age of the population and physicians, and increased doctor visits. This trend will cause the demand for physicians to exceed the supply through at least 2025. The United States will have a shortage of 124,000 full-time doctors by 2025 if physician supply stays the same [8]. The AAMC recommendation of increasing enrollment is widely accepted by US medical schools.

\section{History of internal medicine}

Internal medicine specialists manage chronic illnesses, prevent diseases and evaluate acute symptoms [9]. Most people with many chronic diseases get their care from inter-nists [10]. Internal medicine originated from general medicine

\footnotetext{
${ }^{1}$ Research Students' Association, Medical University of Lublin, Poland

${ }^{2}$ Department of Internal Medicine, Medical University of Lublin, Poland

${ }^{3}$ Department of Nephrology, Medical University of Lublin, Poland
} 
during the end of the 19th century. Its development was related to the idea emerging at that time that diseases came from different disorders in various parts of the body. Earlier, a disease was thought to be due to an imbalance of body fluids. The development of internal medicine as a specialty represents a new way of thinking in clinical medicine, because it ushered in classification, description and advances in chief divisions of clinical medicine. The internist sees the patient from a holistic standpoint, and all applied therapeutic and diagnostic procedures are related to a holistic and comprehensive view of the patient's difficulties [11]. General internal medicine specialists are highly trained physicians who deal with illnesses in all body systems in adult patients, apart from those who need surgery or OB/GYN care. Many diseases, such as rheumatoid/collagen disease, arteriosclerosis, and systemic infections, affect several body systems. Patients have different diseases in many systems as they age. The internal medicine specialist can coordinate the care for multiple system problems and also give continued care to patients with multiple diseases. Internal medicine doctors save costs because they treat multiple problems, whereas medical care for a patient that has many different disorders using many different subspecialists can become very expensive [12].

The largest specialty in the United States is internal medicine. Out of 820,000 physicians internal medicine is practiced by $216,000(26 \%)$. Internal medicine physicians can practice general internal medicine or further specialize in one of the 12 subspecialties of internal medicine. Fifty percent of internists practice general internal medicine. In order for the health care system to be efficient, it must have enough general internal medicine physicians. Internal medicine physicians give patients access to care before conditions reach advanced stages. The overall disease burden is then decreased by thorough prevention and management [9].

\section{History of specialization}

Ophthalmology was the first medical specialty to get its own assessment board. This happened in 1917. There were 20 specialties by the 1970 s. These included primary surgical boards in plastic surgery, urology, orthopedics, colorectal surgery and neurosurgery. Internal medicine still trained general internal medicine physicians but underwent just as much sub-specialization. The American Board of Internal Medicine added 4 subspecialties in the 1940s, 6 in the 1970s, and 10 more after that time. These include pulmonary medicine, cardiology, sleep medicine, geriatric medicine, sports medicine and others. There was concern during the decades that the growing disintegration of medical care would cause the undervaluing and eventual forfeiture of the personal or generalist physician. This concern led to cries for reinforcing and increasing the field of general internal medicine [13].

\section{Shortage of internal medicine physicians}

Because of a very high workload and financial disincentives, fewer than $10 \%$ of internal medicine residents in their first year plan to practice general internal medicine. The majority of those residents will practice as hospitalists or subspecialists. Over $50 \%$ of internal medicine residents pursued a career in general internal medicine in 1998. Currently, only $20 \%$ of internal medicine residents go on to practice general internal medicine. More general internists have left practice than sub-specialists. Twenty percent of general internal medicine physicians have left practice of those starting their career in 1990, however, only 5\% of sub-specialists have left their practice of those starting their career in 1990. As the financial burden and workload increase on general internists, in approximately 10-15 years fewer general internal medicine physicians will be practicing. A disjointed system will then manage chronic diseases. This will worsen health outcomes and increase healthcare costs [10].

\section{Health outcomes and costs in areas with internal medicine physicians}

It is important to have an adequate physician supply in order to improve health outcomes, narrow health disparities and get an adequate physician supply [14]. In the 1950s, $50 \%$ or more medical school graduates pursued internal medicine residencies and $50 \%$ or more finished their residencies and worked in primary care. There are many problems associated with the shortage of internal medicine physicians. It brings inappropriate use of specialists, fragmented care, and less emphasis on prevention. Patients with primary care providers use more preventive health care and have health problems treated at earlier stages, which increases positive health outcomes [15].

Internal medicine doctors give most of the primary care for adults in the United States. In places where primary care medicine is prevalent, the medical system shows higher quality, decreased error rates, better continuity of care and treatment coordination and lower costs. These places include many places in Europe including the United Kingdom, Australia, Canada, Cuba and rural regions of the United States. Patients live longer and are more satisfied with care in these areas. In Europe, three-fourths of doctors are primary care physicians [16]. Increasing the number of primary care physicians is correlated with lower incidence of and mortality from colorectal cancer and cervical cancer, reduced stroke, diagnosing breast cancer at earlier stages, reduced post-neonatal mortality and fewer cases of low birth weight and infant mortality [14]. Patients cared for by family practitioners had a lower rate of screening compared to those cared for by internists, despite equal or higher awareness levels [17].

It is especially important for minorities living in poverty to have access to internal medicine physicians because those minorities can make the most improvement through higherquality primary care [14]. Primary care physicians, compared to specialists, give equal quality of care at decreased cost for patients with lower back pain, diabetes and hypertension. Within each of the United States 50 states, a greater supply of primary care physicians is correlated with decreased costs and greater quality for Medicare beneficiaries. An increased general internal medicine physician-to-population ratio is correlated with a lower cancer mortality, heart disease and total mortality rate. However, a higher specialistto-general internal medicine ratio is associated with increased mortality rates [18]. Half of specialist visits are for routine follow-up, which should be done at primary care physician's offices. Following up with a specialist is expensive and a misuse of expensive care [15]. 


\section{Causes of the decline of internal medicine physicians in the United States}

The current shortage of primary care physicians is due in part to the payment system, which in the United States is a fee-for-service compensation system that pays physicians based on the amount of care they deliver by volume. Diagnosis, counseling, or dispensing prescriptions are services performed by general internal medicine physicians, which are hard to reimburse. However, the many procedures that the specialists provide are much easier to reimburse [15].

One of the reasons for a decline in internal medicine physicians is a lower number of students choosing to go into general internal medicine. In 2009, there was a recent low in the number of medical students choosing training programs focused on internal medicine. However, in 2013, there was a $19 \%$ increase in the number of students choosing such a training program. Nevertheless, it is probable that only 1 out of 5 of these students pursuing a residency in internal medicine will end up practicing general internal medicine. Many of them will go into sub-specialties, like gastroenterology, cardiology, oncology, and pulmonology [19].

\section{Payment of internal medicine physicians in the United States}

The Medscape's data on the highest and lowest earning medical specialties may show why so few students are deciding to pursue a career in internal medicine. The highest paying specialties per year are Radiology: $\$ 315,000$, Orthopedics: $\$ 315,000$, Cardiology: \$314,000, Anesthesiology: \$309,000, and Urology: $\$ 309,000$. The lowest paying specialties are Pediatrics: $\$ 156,000$, Family medicine: $\$ 158,000$, Internal medicine: $\$ 165,000$, Diabetes/endocrinology: $\$ 168,000$, and Psychiatry: $\$ 170,000$ [20]. Internal medicine is one of the lowest paying specialties, which is why students pursue higher paying specialties.

\section{Student debt}

After graduating, medical students have an average student debt of $\$ 160,000$. Many students have loan amount much higher than this. To repay this debt, repayment will be over $\$ 2,000$ per month for 10 years. Specialist physicians' incomes are 1.5 to 4 times greater compared to the incomes of general internal medicine doctors [10].

\section{Depreciation}

A general internist usually does not perform procedures to increase profits. Compensation for procedures is a lot greater compared to using cognitive skills in the healthcare system of the United States [10].

\section{Medicare part B (physician payment portion of Medicare)}

Medicare part B is medical insurance in the United States that covers medical services generally given on an outpatient basis. Since 50 percent of the population older than 65 in the United States have many chronic illnesses, Medicare part B delivers a great amount of the income of an internist. Although Medicare part B premiums have doubled since 2000, the increased money is given to different parts of the healthcare system such as diagnostic imaging, procedures, and medicines. Ten percent or less of the 2006 Medicare part B expenses was used on follow-up office appointments by general internists [10].

\section{Factors that can increase the amount of Internal Medicine Physicians in the United States}

Health care is impacted by the career choices of medical students. Eleven U.S. medical schools were given surveys about educational experiences, like aspects of the specialty of internal medicine, medical school educational experiences, and demographics, in order to understand how to increase the amount of students who become general internal medicine doctors. Factors related with higher probability of selecting internal medicine as a career include interest groups, the core internal medicine clerkship, kinds of patients internists see, satisfaction among internists, scheduling of vocation decision, and academic challenge. Features of the specialty and educational experiences can be remodeled by policy creators to encourage more students to pursue a career in internal medicine [21].

The quality of the continuity clinic experience for internal medicine residents can influence their choice to enter general internal medicine as a specialty. A study was done to see the relationship between internal medicine residents' satisfaction with continuity clinic and interest in general internal medicine careers. Surveys were given to internal medicine residents to assess satisfaction with elements of continuity clinic and the likelihood that residents would choose a career in internal medicine. Participants were from three urban medical centers. The measures were correlations between satisfaction with 32 elements of outpatient clinic in 6 domains, such as personal experience, clinical preceptors, time management, educational environment, ancillary staff and administration, and likelihood of considering a general internal medicine career. Forty-eight percent of residents who completed the surveys intended to enter general internal medicine before beginning their continuity clinic, however, only $38 \%$ did because of continuity clinic. Twenty-eight percent described a lower likelihood as a result of clinic, and $11 \%$ reported higher likelihood as a result of clinic. A significantly greater number of residents were likely vs. unlikely to pursue a career in general internal medicine if they were very satisfied with number of patients seen, faculty mentorship, personal reward from work, time for appointments, continuity with patients and relationship with them. One of the greatest indicators for likelihood to enter general internal medicine due to clinic was being very satisfied with the continuity of relationships with patients. Another indicator was an interest in general internal medicine prior to starting the general internal medicine continuity clinic experience. Resources should be targeted to improve workflow efficiency, ambulatory patient continuity, and increasing preresidency interest in primary care [22].

\section{The future of internal medicine in the United States}

Office visits to primary care physicians will rise from 462 million in 2008 to 565 million in 2025 because of aging and population growth. The United States will need almost 52,000 more primary care physicians by 2025 due to insurance expansion. Population growth will be biggest reason for the increased need for physicians. Population growth will account for 33,000 new physicians, whereas 10,000 extra 
physicians will be required to care for the aging population. The increase in insurance coverage will require a $3 \%$ growth in the workforce; more than 8,000 new physicians will be required because of the increase in insurance coverage [23].

Many chronic illnesses affect around 60 million people in the United States. The United States has the most costly healthcare system per person in the world, however, health outcomes such as longevity data and infant mortality show that the United States healthcare system ranks $15-20^{\text {th }}$ compared to other industrialized countries. Most countries with superior health outcomes have a healthcare system of around $80 \%$ primary care, which include general internal medicine, general practice, obstetrics/gynecology, family practice and pediatrics, and around $20 \%$ sub-specialty care. The United States healthcare system has around 65\% subspecialty care and $35 \%$ primary care [10].

There are reports of 133 million patients in the United States living with a chronic disease and 47 percent of those patients have more than one diagnosis. Sixty percent of patients with diabetes and 53 percent of patients with hypertension had four or more disorders diagnosed in 1996. A typical patient with diabetes has also osteoarthritis, hypertension, depression and obesity. A health system based only on specialists will need many different specialists to treat the multitude of diagnoses that a primary care physician takes care of in one visit. Comorbidities intermingle with each other. Arthritis makes it harder for diabetic patients to exercise. Specialists are better than primary care physicians at treating some specific diagnoses and can provide procedural interventions that primary care physicians are not trained to do, however, general internal medicine doctors are better at handling many issues that come with having many comorbid diseases [18].

The greatest amount of chronic illness visits happen in primary care practices: 71 percent for depression, 76 percent for asthma, 79 percent of visits for hypertension, 83 percent for hyperlipidemia, 67 percent for chronic obstructive pulmonary disease, 72 percent for diabetes and 66 percent for congestive heart failure are visits to primary care physicians rather than specialists. The U.S. population is projected to increase by 18 percent from 2005 to 2025 . There will be a 73 percent increase in the number of people over sixtyfive. People at that age look for care from general internal physicians at a much greater rate than people under sixty five. However, it is estimated that there will be a 27 percent shortage in adult generalist physicians by 2025 . The Council on Graduate Medical Education predicts that the ratio of generalist physicians to population will decrease from 2005 to 2020 by 9 percent [18].

\section{Policy changes that may increase the number of internal medicine physicians in the United States}

Creating national workforce policy that approximates the need for different categories of public health and health care personnel, and regulates health care training according to this estimation will increase the amount of general internal medical physicians in the United States. A national policy goal should be 50 percent of U.S. clinicians practicing in primary care. This policy can be put into place by paying primary care providers and specialists similar pays so that the generalist-to-population ratio increases, changing the financing of graduate medical education, and encouraging the education of health care personnel from underrepresented populations [18].

\section{Moves made to increase interest in internal medicine}

There have been some moves made to increase interest in general internal medicine. Massachusetts has laws to forgive medical school loans for physicians who practice primary care within the state [18]. The Affordable Care Act will bring many changes to the supply of internal medicine physicians in the United States. The Affordable Care Act specifies increased payments for three primary care medical specialties: Family Medicine, General Internal Medicine and Pediatrics [24].

Demand for internal medicine care professionals outweigh that of surgeons, cardiologists, radiologists and orthopedic surgeons according to physician recruitment firms [25]. The median earnings for general internal medicine physicians increased by more than 5\% in 2011, up from 2010 according to the Medical Group Management Association's Physician Compensation and Production Survey: 2012 Report Based on 2011 Data [26]. This is due to the increasing employment of physicians by hospitals, and a growing focus on primary care providers. The government and private health care providers are seeing the need for the general internal medicine physician. There is hope for the future of internal medicine.

\section{Internal medicine in Poland}

In Poland, the speciality procedure in internal diseases lasts five years. The recruitment into the speciality is based on the results of the National Medical Licensing Examination. Physicians specialise in internal diseases in departments (clinics) of internal diseases or specialist units associated with internal diseases (cardiology, gastroenterology, rheumatology, and endocrinology). The speciality training is supervised by a specialist in internal medicine. The internal medicine residency program includes trainings in intensive care (60 days), cardiology (60 days), pulmonology (30 days), endocrinology (20 days), diabetology (10 days), gastroenterology (30 days), nephrology (20 days), rheumatology and rehabilitation (20 days), haematology (20 days), infectious diseases (20 days), neurology (10 days) and psychiatry (10 days). Residents specialising in internal diseases should acquire the following skills: history taking, physical examination, interpretation of laboratory results, performance and interpretation of ECG, unassisted interpretation of chest $\mathrm{X}$-ray, collection of the material for examinations (venous and arterial blood, urine, biological fluids), decompression of the pleural cavity, decompression of the peritoneum, urinary catheterisation, insertion of a gastric tube, funduscopic examination, and keeping medical records. The final speciality exam consists of a multiple-choice (written) test, as well an oral and practical part. After passing the exam, the physician-specialist can be the head of the department (clinic) or ward of internal diseases. Moreover, having completed the speciality in internal diseases, physicians are entitled to subspecialise in cardiology, gastroenterology, rheumatology, endocrinology, pulmonology, allergology, angiology and hypertensiology [27]. 
The medical speciality of internal medicine combines basic sciences and more detailed specialities that originated from internal medicine over the past century. Thanks to the achievements in it, internal medicine was called "the queen of medical sciences". The holistic approach to patients determines the highest possible effectiveness of medical services. Such an approach to health- and illness-related problems has been the mission of the science of internal diseases since its dawn, constituting one of the unchangeable principles distinguishing internal medicine from other medical disciplines. By the end of the 20th century, in the majority of university centres old departments (clinics, wards) of internal diseases were replaced with narrowly specialised departments. In local hospitals, on the other hand, internal medicine wards have remained the dominating conservative units treating adults. This created a false impression of the twilight of internal medicine or its distancing from the university centres. At present, the field of internal medicine has limited rights to exist, which is attributable to numerous reasons, mainly to considerable advances in medicine. Internists themselves contributed to this situation by giving the scope for activity to sub-specialities. Departments of internal diseases are responsible for a large proportion of hospital expenditure (15-16\%). The occupancy rate of internal medicine departments is extremely high (usually over $80-100 \%$, additional beds, poor social conditions). Most patients treated in these departments are old and suffer from multiple diseases. Due to this multiplicity, their hospitalisations are long. They are treated simultaneously for various ailments and it is difficult to determine the main cause of their hospitalization. The National Health Fund pays only for treatment of the underlying disease and not all the co-morbidities that patients are treated for; therefore, departments of internal medicine become the units most heavily contributing to hospital debts [28].

Moreover, hospitalizations and procedures performed in internal medicine departments are poorly priced by the National Health Fund and the departments in question are increasingly indebted. Additionally, outpatient clinics of internal diseases, which provided pre- and post-hospital specialist care, have been closed. Such a situation leads to the lack of continuity of medical care for patients referred to hospitals, in particular those discharged from them, hence increased incidence of hospitalizations of the same patients, which increases the treatment costs and debts of internal medicine departments. Compared to narrowly specialised colleagues, salaries of internists are relatively low whereas the scope of knowledge required to complete the speciality is large. Therefore, the speciality is not popular among physicians finishing their studies. Physicians of narrow specialities are perceived by the society as "better" than internists. During the privatisation of the Polish Health Service, some departments of internal diseases were closed due to the lack of cost-effectiveness. The remaining departments are being supplanted by those of narrower specialities, which are more cost-effective $[29,30]$.

Each hospital should have a department (ward) of internal medicine cooperating with other sub-units. Accident and Emergency Departments admit daily many patients who should be admitted and diagnosed in the departments of internal medicine. Social and economic aspects are essential for the development of internal medicine, particularly the increasing number of elderly patients and those treated for multiple diseases. The fall or weakening of internal medicine will lead to social, organization- and system-related problems in Polish Health Service.

\section{Internal medicine trends in Poland and the United States}

The trend for internal medicine in Poland is following the trend internal medicine followed in the United States. The increasing privatization of the health system in Poland is favouring the sub-specialization of many doctors and many are choosing to specialize in fields that are compensated more than internal medicine physicians. In order for this trend in Poland to be reversed, there must be some policy changes. To stop this trend, Poland can make moves to increase the interest in internal medicine just as the United States has done. Policies that can be adopted include decreasing the payment gap between internal medicine physicians and other specialists and increasing other incentives for internal medicine physicians. Policies can also be put into place requiring new doctors to practice internal medicine for a certain amount of years. Medical schools in Poland can make a point to accept students who are committed to specializing in internal medicine. Entering medical school, students can sign a contract that commits them to practice internal medicine for a definite time after graduation. Policy makers and educators must implement new policies to reverse the decrease in practicing internal medicine physicians.

\section{REFERENCES}

1. About Internal Medicine: What's an "Internist"? Philadelphia: American College of Physicians; c2013. [http://www.acponline.org/patients_families/about_internal_medicine/]

2. Bloomfield AL. Origin of the term "Internal Medicine": Guest Editorial. JAMA. 1959;169(14):1628-9.

3. Internal Medicine. Tampa: American Board of Physician Specialties; c2013. [http://www.abpsus.org/internal-medicine]

4. Certification Matters. Philadelphia: American Board of Internal Medicine; c2011-2013. [http://www.certificationmatters.org/abms-memberboards/internal-medicine.aspx]

5. Steps to Internal Medicine Certification. Tulsa: American Osteopathic Board of Internal Medicine Certification and Recertification Web Center; c2011. [http://www.aobim.org/]

6. The Impending Collapse of Primary Care Medicine and Its Implications for the State of the Nation's Health Care: A Report from the American College of Physicians January 30, 2006. Philadelphia: American College of Physicians; c2006. [http://www.acponline.org/advocacy/advocacy in action/state of the nations healthcare/assets/statehc06 1.pdf.]

7. Colwill JM, Cultice JM, Kruse RL. Will Generalist Physician Supply Meet Demands of an Increasing and Aging Population? Health Aff. 2008;27(3):w232-w241.

8. Dill MJ, Salsberg ES. The Complexities of Physician Supply and Demand: Projections Through 2025. Washington D.C: Association of American Medical College; c2008. [http://www.innovationlabs.com/ pa_future/1/background_docs/AAMC $\% 20$ Complexities $\% 20$ of $\% 20$ physician\%20demand,\%202008.pdf]

9. Internal Medicine: Ambulatory care internal medicine has a critical role in the US health care system. New Haven: Yale School of Medicine; c2012. [http://medicine.yale.edu/intmed/education/ambmedclerkship/ rationale 5.aspx]

10. Save The Internist. (place unknown). Montana Internist Association; c2011-2014. [http://www.mtinternist.org/Save_The_Internist.html]

11. Kucharz E. The man behind the journal: Editors-in-Chief of the Polish Archives of Internal Medicine (1923-2013). Pol Arch Med Wewnętrz. 2013;123(7-8):339-46. 
12. Baillie H. General internal medicine: A core specialty in jeopardy. BC Med J. 2005;47(7):377-8.

13. Cassel C, Reuben D. Specialization, subspecialization, and subsubspecialization in internal medicine. NEJM. 2011;364(12):1169-73.

14. Hawkins D, Proser M, Schwartz R. Health Reform and Healthcare Homes: The Role of Community Health Centers. Harvard Health Policy Rev. 2007;8(2). [http://www.allhealth.org/briefingmaterials/HawkinsHarvardHealthPolicyReview-020908-1391.doc]

15. Primary Care Shortage: Issue Modules, Background Brief. (place unknown). The Kaiser Family Foundation, KaiserEDU.org; c2011. [http:// www.wcl.american.edu/secle/materials/Fall_2012/Next_Steps_in Health_Reform/TAB\%2012.Background-Brief.pdf]

16. Linden RA. The Rise and Fall of the American Medical Empire: A Trench Doctor's View of the Past, Present, and Future of the U.S. Healthcare System. North Branch: Sunrise River Press; 2010. p.304.

17. Higgins A, Doubeni A, Phillips K, et al. Self-reported colorectal cancer screening of Medicare beneficiaries in family medicine vs. internal medicine practices in the United States: a cross-sectional study. BMC Gastroenterol. 2012;12:23.

18. Bodenheimer T, Chen E, Bennett H. Confronting The Growing Burden Of Chronic Disease: Can The U.S. Health Care Workforce Do The Job? Health Affairs. 2009;28(1):64-74.

19. Kaplan K. Match Day 2013 results are good for future internal- medicine patients. Los Angeles Times. 2013 Mar 15. [http://articles.latimes. com/2013/mar/15/news/la-heb-doctors-match-day-internal-medicine-20130315]

20. Adams S. Why Do So Many Doctors Regret Their Job Choice? Forbes. 2012 Apr 27. [http://www.forbes.com/sites/susanadams/2012/04/27/ why-do-so-many-doctors-regret-their-job-choice/]

21. Durning S, Elnicki D, Cruess D, et al. Almost internists: analysis of students who considered internal medicine but chose other fields. Academic Medicine. J Assoc Am Med Colleges. 2011;86(2):194-200.
22. Peccoralo L, Tackett S, Ward L, et al. Resident satisfaction with continuity clinic and career choice in general internal medicine. J General Int Med. 2013;28(8):1020-7.

23. Petterson S, Liaw W, Phillips R, et al. Projecting US Primary Care Physician Workforce Needs: 2010-2025. Ann Fam Med. 2012;10(6):503-9.

24. Qs \& As on the Increased Medicaid Payment for Primary Care. Baltimore: Medicaid.gov; c2013. [http://www.medicaid.gov/AffordableCareAct/Provisions/Downloads/Q-andA-Managed-Care-Increased-Payments-for-PCPs.pdf]

25. The future of internal medicine careers (place unknown): EzineMark. com; c2005-2013. [http://medicine.ezinemark.com/the-future-of-internal-medicine-careers-7d3827f91456.html]

26. Bowers L. Family, internal medicine physician compensation up over previous year. Medical Economics. 2012 Jul. [http://medicaleconomics.modernmedicine.com/medical-economics/news/modernmedicine/ modern-medicine-news/family-internal-medicine-physician-compen]

27. Program specjalizacji w chorobach wewnętrznych. [http://www.cmkp. edu.pl/wp-content/uploads/2013/07/Choroby-wewnetrzne-podstawowy-2005.pdf]

28. Imiela J. Ogólna sytuacja interny w Polsce. [http://www2.mz.gov.pl/ wwwfiles/ma_struktura/docs/zal_4_26052010.pdf].

29. Derkacz M. Silna interna - czyli nie detronizować królowej medycyny! Służba Zdrowia. 2010;9-16:15-6.

30. Imiela J. Propozycje poprawy sytuacji interny w Polsce w 2011 roku. [http://www2.mz.gov.pl/wwwfiles/ma_struktura/docs/25022011_zal1_ sytuacja_interny.pdf]

\section{Corresponding author}

Andrzej Prystupa, MD

Department of Internal Medicine, Medical University of Lublin

16 Staszica Str., 20-081 Lublin, Poland

E-mail: aprystup@mp.pl 